\title{
PREPARATION AND EVALUATION OF CONTROLLED RELEASE FLOATING MICROSPHERES OF REPAGLINIDE: OPTIMIZATION AND IN-VITRO STUDIES
}

\author{
MEGHA SHARMA ${ }^{* 1}$, SEEMA KOHLI ${ }^{2}$, ABHISEK PAL ${ }^{3}$ \\ ${ }^{1}$ Department of Pharmacy, Shri Ram Institute of Technology (Pharmacy), Jabalpur, Madhya Pradesh, India. ${ }^{2}$ Department of Pharmacy, \\ KN Polytechnic College, Jabalpur, Madhya Pradesh, India. ${ }^{3}$ Department of Pharmacy, School of Pharmaceutical Sciences, \\ Siksha '0' Anusandhan University, Bhubaneswar, Odisha, India. Email: meghapharma@rediffmail.com
}

Received: 22 September 2016, Revised and Accepted: 26 December 2016

ABSTRACT

Objective: To develop and evaluate floating microspheres of repaglinide (RG).

Materials and Methods: RG loaded noneffervescent microspheres of different ratios of ethylcellulose (EC) and hydroxypropyl methylcellulose (HPMC K4M) were prepared using polyvinyl alcohol as emulsifier by solvent evaporation technique. Various process variables such as polymer ratio, stirring speed, concentration of drug, and emulsifying agent were studied. Compatibility of drug and polymers was studied by Fourier-transform infrared spectroscopy (FTIR). Characterization, in-vitro evaluation, and kinetic studies were performed.

Results: FTIR spectra have revealed no drug-excipient incompatibility. The average particle size of microspheres was in the range of $312-359 \mu$ m. The results showed that floating microspheres were successfully prepared with good yield (56.15-64.3\%), high entrapment efficiency (58.22-70.14\%), and good floating behavior (63.1-76.2\%), respectively. In-vitro release data indicates appreciable amount of drug is released (62.28-73.27\%) from the microspheres in gastric fluid. The mechanism of drug release founds to follow first order kinetics $\left(\mathrm{r}^{2}=0.986\right)$.

Conclusion: The developed floating microspheres of RG may be used for prolonged drug release for at least 12 hrs, thereby improving bioavailability and patient compliance.

Keywords: Repaglinide, Compatibility, Kinetic, Ethylcellulose.

(C) 2017 The Authors. Published by Innovare Academic Sciences Pvt Ltd. This is an open access article under the CC BY license (http://creativecommons. org/licenses/by/4. 0/) DOI: http://dx.doi.org/10.22159/ajpcr.2017.v10i3.15310

\section{INTRODUCTION}

Diabetes mellitus is commonly occurring, one of the oldest and chronic noncommunicable disease. It is a serious, costly and heterogeneous metabolic disorder characterized by altered carbohydrate, lipid and protein metabolism [1]. Diabetes mellitus is the fourth or fifth leading cause of death in most developed countries with the substantial evidence to be epidemic in many developing and newly industrialized countries, affecting about $25 \%$ of the population [2]. Diabetes results in a state of chronic hyperglycemia (peripheral insulin resistance), glycosuria, polyuria, polydipsia (excessive thirst), polyphagia (constant hunger), sudden weight loss, ketoacidosis, ketonuria (urinary ketones), etc. [3]. Type II diabetes is referred to as insulin resistance, caused by greatly diminished sensitivity of target tissues to the metabolic effects of insulin. Type II diabetes accounts for $80-90 \%$ of all cases of diabetes. Type II diabetes is associated with increased plasma insulin concentration which occurs as a compensatory response by the pancreatic $\beta$-cells for the decrease in carbohydrate utilization and storage and the resultant increase in blood glucose [4].

Repaglinide (RG) is first member of meglitinide class and an oral hypoglycemic agent, used in the treatment of Type II diabetes mellitus. It binds to specific site on pancreatic $\beta$-cells, blocks the adenosine triphosphate-dependent potassium channel and thereby stimulates insulin release [5]. Due to low bioavailability (50\%) and short half-life (1 hr) RG requires frequent dosing before meals and thus imposing various side effects such as skeletal muscles pain, headache, and gastrointestinal tract (GIT) effects [6]. To reduce these side effects and increase duration of action by controlling the release of drug slowly, the drug is encapsulated within polymeric membrane, thus maintain its concentration for longer duration and increase effectiveness. Therefore, the drug is suitable target for developing floating delivery system as it has the characteristics of short lasting action, fast clearance, enzymatic stability, and absorption throughout GIT. The objective of this research work was to develop multiparticulate floating drug delivery system of RG with ethylcellulose (EC) and hydroxypropyl methylcellulose (HPMC) $\mathrm{K} 4 \mathrm{M}$ as release control polymer.

Oral route is the most preferred route having advantage of easy administration, handling, and patient convenience. Gastroretentive delivery systems are mainly designed for drugs having narrow absorption window. Such systems get retain at the site of absorption and release drug in controlled manner for longer time. Several such approaches were developed such as swelling and expanding systems, high-density systems, ion-exchange resin systems, bio/mucoadhesive systems, raft forming systems, superporous hydrogel systems, magnetic systems, bioadhesive liposomal systems, and modified shape systems [7]. Floating drug delivery system has drawn much attention nowadays due to buoyancy action having greater safety for clinical uses and having no effect of peristaltic movement of the GIT [8]. Drugs having short half-life require frequent dosing as they eliminated quickly from blood circulation, therefore, to increase the bioavailability [9] of such drugs controlled release formulations were prepared. Several categories of drugs having local action and primarily absorbed in the stomach, poorly soluble in alkaline $\mathrm{pH}$, narrow absorption window, unstable in the intestine or colonic environment are suitable candidates for formulating as floating delivery system [10]. In the recent literature, various floating microspheres for encapsulation of different drugs such as rabeprazole sodium [11] and dextromethorphan hydrobromide [12] have been reported. 


\section{MATERIALS AND METHODS}

\section{Materials}

RG was procured as gift sample from Torrent Pharmaceuticals, Ahmedabad, India. EC and HPMC K4M were purchased from Himedia Chemicals, India. Ethanol, dichloromethane (DCM), and other solvents were purchased from SD Fine Chemicals Mumbai, India. All other chemicals used were of analytical grade.

\section{Compatibility study}

Compatibility study of drug and polymer was studied by Fouriertransform infrared (FTIR) spectrophotometer (Shimadzu 8400, Japan) instrument. IR spectra of pure drug and mixture of drug with EC and HPMC K4M were analyzed and recorded.

\section{Formulation of floating microspheres}

Solvent diffusion evaporation technique with slight modification [13] was employed for preparation of formulations. Both the polymers were dissolved in mixture of dichloromethane (DCM) and ethanol (1:1). To this solution drug and $0.1 \%$ of polyethylene glycol was dispersed and stirred by means of high-speed mechanical stirrer (Remi Equipment, India) for 15 mins. The organic phase was then slowly poured into $80 \mathrm{ml}$ of water containing $0.46 \% \mathrm{w} / \mathrm{v}$ of polyvinyl alcohol (PVA) (emulsifier) and stirred for $1 \mathrm{hr}$. Formulation design of microspheres is shown in Table 1. The microspheres were washed thoroughly with distilled water and dried for $1 \mathrm{hr}$ at room temperature. Process variables such as polymer ratio, drug:polymer ratio, concentration of emulsifier, and stirring rate were studied during formulation.

\section{Characterization of microspheres \\ Micromeritics properties}

Microspheres were characterized for micromeritics properties such as particle size, tapped density, bulk density, and angle of repose. Particle size is measured using an optical microscopy and mean particle size was calculated by measuring 200-300 particles with calibrated ocular micrometer. Fixed funnel method is used to measure the flow characteristics. Tapped density was determined using tapping method [14].

\section{Morphology}

The shape and surface morphology of the microspheres were examined by scanning electron microscopy (SEM) (Jeol JSM-1600, Tokyo, Japan).

\section{Floating behavior}

$50 \mu \mathrm{g}$ of the microparticles were placed in SGF (pH 1.2, $100 \mathrm{ml}$ ) containing Tween $20(0.02 \mathrm{w} / \mathrm{v} \%)$ and stirred at $100 \mathrm{rpm}$. After $12 \mathrm{hrs}$ buoyant and settled microparticles were separated, dried, and weighed. The buoyancy was calculated using following formula:

Buoyancy $(\%)=\mathrm{W}_{\mathrm{f}} /\left(\mathrm{W}_{\mathrm{f}}+\mathrm{W}_{\mathrm{s}}\right) \times 100$

Where, $W_{f}$ and $W_{s}$ are the weights of the floating and settled microparticles, respectively.

\section{Entrapment efficiency and yield}

To $10 \mathrm{ml}$ of ethanol, $50 \mu \mathrm{g}$ of microparticles were crushed, suspended and was kept for $12 \mathrm{hrs}$ for extraction of drug. RG content was determined from the filtrate after suitable dilution spectrophotometrically at $247 \mathrm{~nm}$. The percentage drug entrapment and yield [15] were calculated as follows:

$\%$ Drug entrapment $=($ Calculated drug content $/$ Theoretical drug content) $\times 100$

$\%$ Yield $=$ (Total weight of floating microparticles $/$ Total weight of drug and polymer) $\times 100$

\section{In-vitro drug release studies}

In-vitro dissolution study was carried out in a paddle type six-station dissolution test apparatus (Veego, VDA-6DR, and USP Std.). Floating microspheres equivalent to $16 \mu \mathrm{g}$ of the drug were placed in $0.1 \mathrm{~N} \mathrm{HCl}$ $(1.2 \mathrm{pH})$ containing Tween $20(0.02 \mathrm{w} / \mathrm{v} \%)$ maintained at $37 \pm 0.5^{\circ} \mathrm{C}$ at a rotation speed of $100 \mathrm{rpm}$. Perfect sink condition was maintained. $1 \mathrm{ml}$ sample was withdrawn after every hr, filtered and analyzed spectrophotometrically at $247 \mathrm{~nm}$. All experiments were conducted in triplicate.

\section{Evaluation of in-vitro release kinetics}

The kinetics of drug release can be known by substituting the in-vitro release data to different kinetic models such as zero order (\% cum. drug retained vs. t), first order (log \% cum. drug release vs. t), Higuchi model (\% cum. drug release vs. square root of time), and Peppas exponential equation (log \% cum. drug release vs. log time). Regression coefficient $\left(\mathrm{r}^{2}\right)$ values were calculated for the linear curves obtained by regression analysis [16].

\section{RESULTS AND DISCUSSION}

\section{Compatibility studies}

Interaction of drug and polymers were studied by FTIR and spectra's were shown in Fig. 1. Spectra of RG shows peaks at 3308 ( $\mathrm{NH}$ stretching), 2947 (CH stretching), $1220\left(\mathrm{CH}_{3}\right)$, and $1685 \mathrm{~cm}^{-1}$ $(\mathrm{C}=0)$. Spectra of EC show a sharp band at 2929 and $3481 \mathrm{~cm}^{-1}$ associated with a $\mathrm{CH}$ and $\mathrm{OH}$ stretching vibrations, respectively. Spectra of HPMC K4M show band at 3295 and $2931 \mathrm{~cm}^{-1}$ of OH and CH stretching vibrations, along with ethereal C-O-C group stretching vibration between 1192 and $1073 \mathrm{~cm}^{-1}$. IR spectra of mixture of drug with EC and HPMC K4M shows peaks at $3308 \mathrm{~cm}^{-1}$ (NH stretching), $2934 \mathrm{~cm}^{-1}$ (CH stretching), and $1687 \mathrm{~cm}^{-1}$ ( $\mathrm{C}=0$ ) thereby, having no interaction, as there was no major shift in the absorption bands of drug was found.

\section{Formation of microspheres}

The floating microspheres were prepared by solvent diffusion evaporation technique using EC and HPMC K4M polymers. Organic phase containing suspension of polymer and drug in 1:1 ratio of ethanol and DCM was poured into an aqueous phase containing PVA. The organic solvents get rapidly distributed into the external aqueous phase

Table 1: Formulation and optimization of microspheres

\begin{tabular}{|c|c|c|c|c|}
\hline Batch code & Ratio of EC:HPMC & Concentration of emulsifying agent (\%) & Stirring rate (rpm) & Amount of drug $(\mu \mathrm{g})$ \\
\hline $\mathrm{C} 1$ & $1: 1$ & 0.46 & 900 & 10 \\
\hline $\mathrm{C} 2$ & $1: 2$ & 0.46 & 900 & 10 \\
\hline $\mathrm{C} 3$ & $1: 3$ & 0.46 & 900 & 10 \\
\hline $\mathrm{C} 4$ & $1: 2$ & 0.46 & 600 & 10 \\
\hline $\mathrm{C} 5$ & $1: 2$ & 0.46 & 1200 & 10 \\
\hline C6 & $1: 2$ & 0.66 & 900 & 10 \\
\hline $\mathrm{C} 7$ & $1: 2$ & 0.86 & 900 & 10 \\
\hline $\mathrm{C} 9$ & $1: 2$ & 0.46 & 900 & 30 \\
\hline
\end{tabular}

EC: Ethylcellulose, HPMC: Hydroxypropyl methylcellulose 


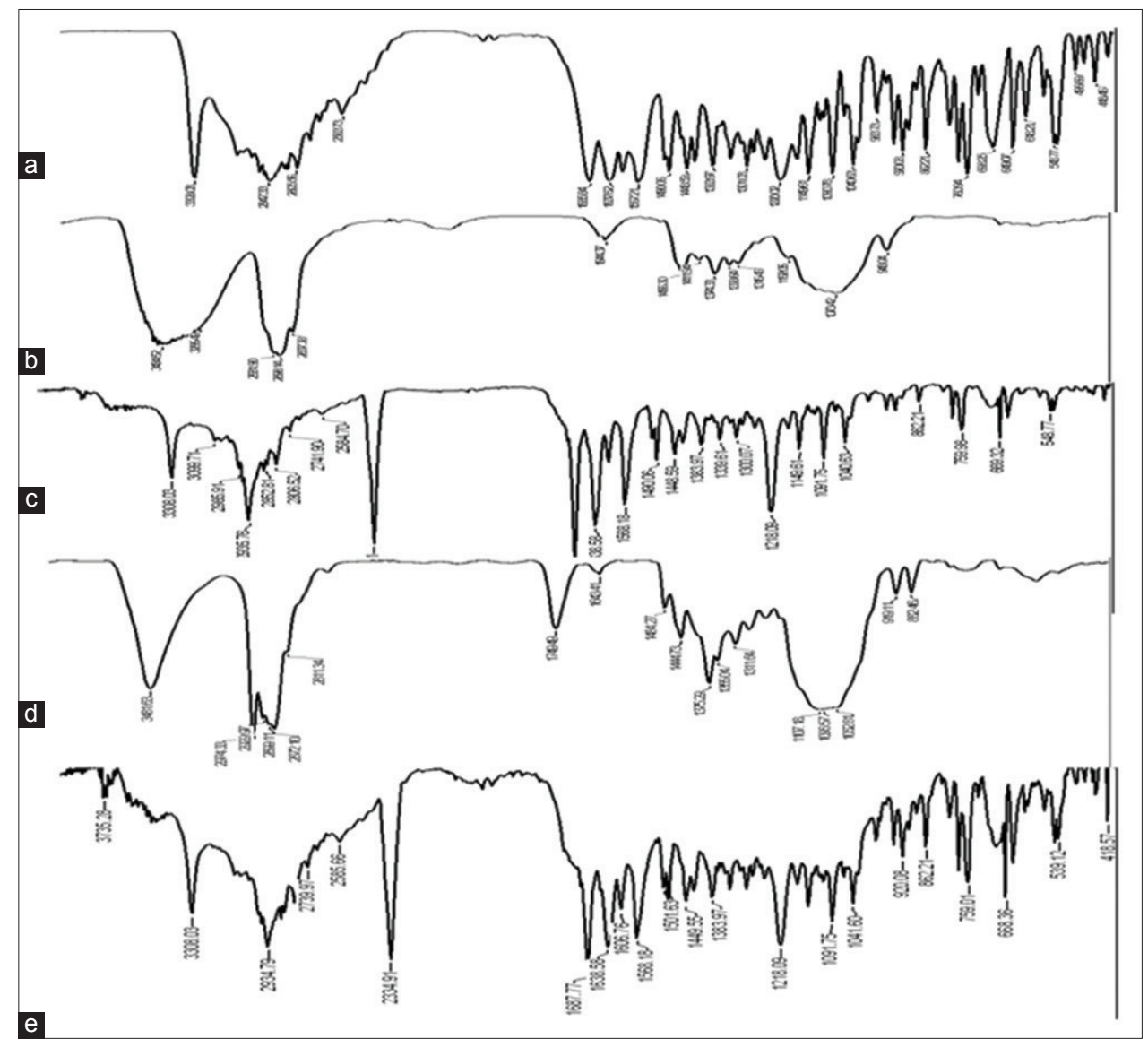

Fig. 1: Infrared spectra: (a) Repaglinide (RG), (b) hydroxypropyl methylcellulose (HPMC) K4M, (c) mixture of RG and HPMC K4M, (d) ethylcellulose (EC), and (e) mixture of RG and EC

and microspheres were formed by precipitation of polymer around the drug particle due to the evaporation of organic phase [15].

\section{Micromeritics properties}

The micromeritics properties were evaluated for all the batches of the microspheres. The angle of repose values ranged between $31.81 \pm 1.11$ and $39.85 \pm 2.84$ indicating good flow characteristics. The bulk and tapped density were found in the range of $0.64 \pm 0.45$ to $0.70 \pm 0.36$ and $0.83 \pm 0.25$ to $0.87 \pm 0.35 \mathrm{~g} / \mathrm{cm}^{3}$, respectively, (Table 2) indicating the nonaggregated nature of prepared microspheres.

\section{Morphology}

SEM photographs reveal the spherical orientation with smooth and dense outer surface of microspheres prepared as shown in Fig. 2. The ruptured surface showing hollow nature of microspheres in the interior which makes them to float on the GIT fluid.

\section{Floating behavior, drug entrapment, and yield}

Flow ability was observed by calculating percent buoyancy and was found that more than $63.18 \%$ microspheres remained floating at the end of $12 \mathrm{hrs}$. Increase in concentration of HPMC K4M increases buoyancy. Increase in stirring rate from 600 to 1200 decreases buoyancy from $75.1 \%$ to $67.2 \%$ due to reduction in size of the particle at high-speed of rotation. Percent yield was $>56.1 \%$ for all the formulations and it decreases with increase of HPMC K4M concentration may be due to migration of hydrophilic polymer into continuous phase forming agglomerates. On increasing stirring speed from 600 to $900 \mathrm{rpm} \%$ yield increases (59.24-67.41\%), whereas on further increase in speed of rotation to $1200 \mathrm{rpm}$ it decreases [17]. Figs. 3 and 4 show the effect of stirring rate and concentration of emulsifier on various parameters studied. No significant effect of increasing emulsifier concentration on percentage yield was observed.

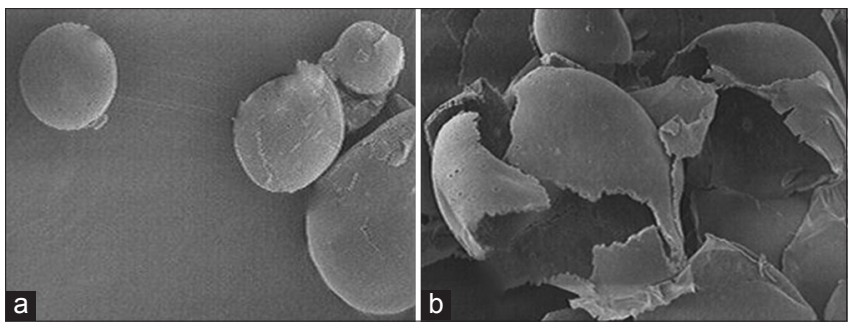

Fig. 2: Scanning electron microscopy images: (a) Spherical shaped microsphere and (b) ruptured surface showing hollow nature of microspheres

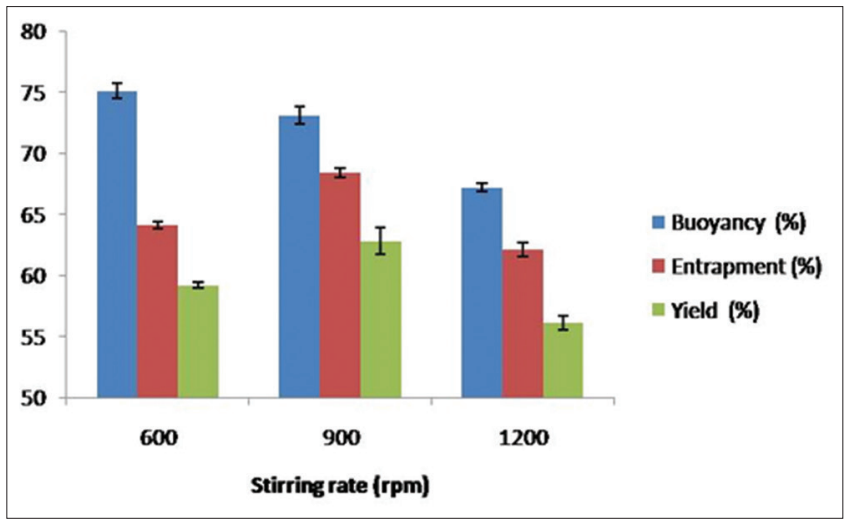

Fig. 3: Effect of stirring rate on various optimization parameters All data are represented as mean \pm standard deviation $(n=3)$ 
Table 2: Results of micromeritics properties

\begin{tabular}{llll}
\hline Batch code & Mean particle size & Bulk density & Tapped density \\
\cline { 4 - 4 } C1 & $324 \pm 11.2$ & $0.68 \pm 0.24$ & $0.84 \pm 0.12$ \\
C2 & $330 \pm 24.0$ & $0.67 \pm 0.48$ & $0.85 \pm 0.47$ \\
C3 & $349 \pm 24.2$ & $0.66 \pm 0.54$ & $0.84 \pm 0.34$ \\
C4 & $345 \pm 77.2$ & $0.67 \pm 0.31$ & $0.83 \pm 0.25$ \\
C5 & $312 \pm 92.1$ & $0.70 \pm 0.36$ & $35.57 \pm 1.82^{\circ}$ \\
C6 & $321 \pm 110.5$ & $0.68 \pm 0.41$ & $37.34 \pm 2.11^{\circ}$ \\
C7 & $314 \pm 82.3$ & $0.69 \pm 0.48$ & $39.85 \pm 2.84^{\circ}$ \\
C8 & $348 \pm 93.5$ & $0.65 \pm 0.21$ & $36.23 \pm 1.54^{\circ}$ \\
C9 & $359 \pm 72.7$ & $0.64 \pm 0.45$ & $37.97 \pm 1.27^{\circ}$ \\
\hline
\end{tabular}

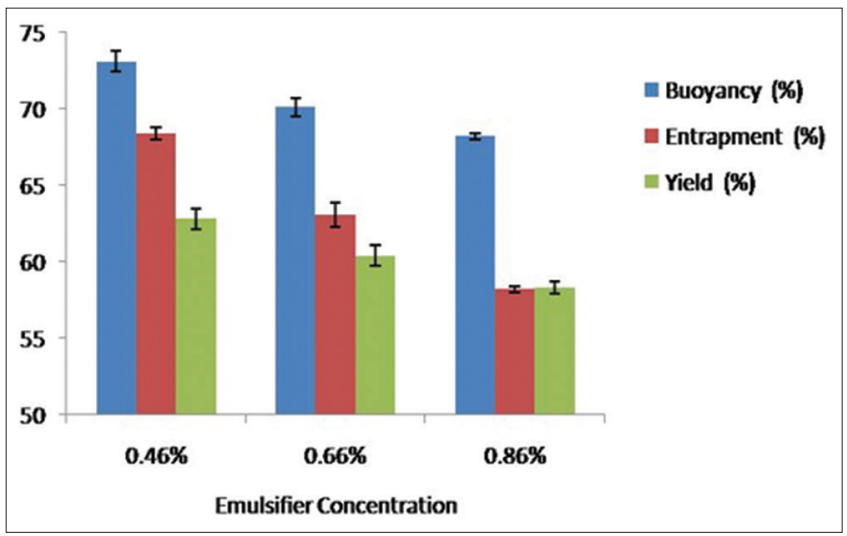

Fig. 4: Effect of emulsifier concentration on various optimization parameters. All data are represented as mean \pm standard deviation $(n=3)$

The value of entrapment efficiency ranged from $58.22 \%$ to $70.15 \%$ for all the formulation. The high entrapment of RG was found to be due to its poor water solubility. The extent of loading influenced the particle size distribution of microspheres. Increasing polymer concentrations slightly increases drug loading. Increase in stirring speed from 600 to $900 \mathrm{rpm}$ (64.15-67.18\%) increases entrapment, which decreases as stirring speed increased to $1200 \mathrm{rpm}$, which is due to reduced size of microspheres formed at higher speed of rotation [18].

\section{In-vitro drug release and kinetic studies}

Release of drug from prepared formulations was evaluated in $\mathrm{pH} 1.2$ for $12 \mathrm{hrs}$. Release of drug from any of the formulation has no burst effect, hence showing homogenous drug distribution. Not much effect on release was observed with increasing HPMC K4M polymer because of less hydration of high viscosity polymer.

On increasing speed of rotation from 600 to $1200 \mathrm{rpm}$, there is an increase in drug release from $64.31-72.41 \%$. As the particle size is reduced due to increased stirring, large surface area is exposed to release. Increase in concentration of drug has no significant effect on drug release. On the basis of good results of buoyancy, drug content, size, yield and release $\mathrm{C} 2$ was selected as optimized formulation.

The data obtained for in-vitro release were fitted into equations for the zero order, first order, Higuchi, and Peppas model. The data were interpreted on the bases of regression coefficients obtained. In-vitro release data of optimized formulation follows first order kinetics $\left(r^{2}=0.986\right)$ (Fig. 5) followed by Peppas and Higuchi model. Peppas equation has been applied to explain the release mechanism. Value of slope (n) was calculated and is $\leq 0.89$, showing coupling of diffusion and erosion mechanism called anomalous diffusion, indicating that drug release is controlled by more than one process. From these results, it can be concluded that release of drug follows first order, diffusion, and erosion mechanism.

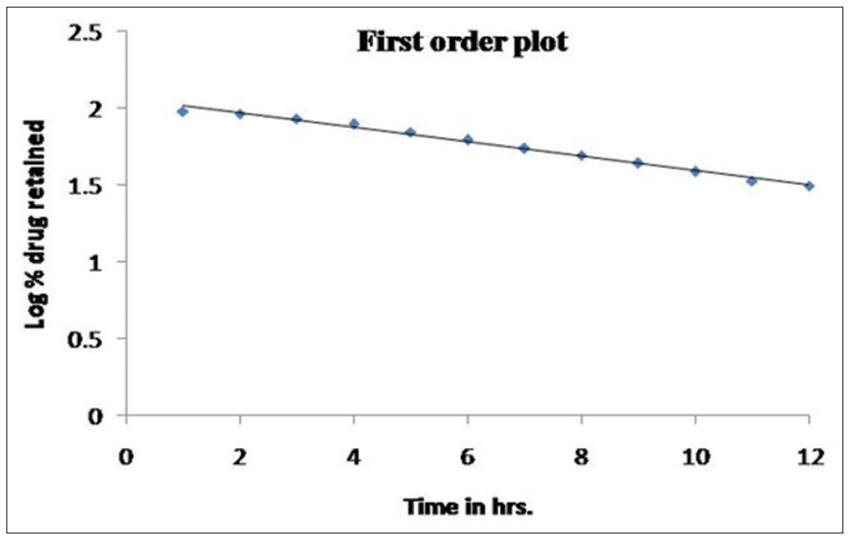

Fig. 5: First order plot of optimized formulation (C2)

\section{CONCLUSION}

The formulation of RG loaded EC and HPMC K4M microspheres were successfully prepared. Different investigations on formulation, characterization, in-vitro release, and kinetic study were carried out. The development of formulation and optimization yielded the desired microspheres with drug release up to $12 \mathrm{hrs}$ and with advantage of floatability in gastric juice for prolonged time. The proposed optimized formulation depicts an effective way to prolongs drug release which are safe and in need of pharmaceutical industry as an alternate for effective management of noninsulin-dependent diabetes mellitus.

\section{ACKNOWLEDGMENT}

The authors are grateful to the management of Rewa Siksha Samiti, Jabalpur, for providing the facility to carry out the research work. Also thankful to M/s Torrent Pharmaceuticals, Ahmedabad, for providing drug as gift sample.

\section{REFERENCES}

1. Das AV, Padayatti PS, Paulose CS. Effect of leaf extract of Aegle marmelose (L.) Correa ex Roxb. on histological and ultra-structural changes in tissues of streptozotocin induced diabetic rats. Indian J Exp Biol 1996;34(4):341-5.

2. Cline GW, Petersen KF, Krssak M, Shen J, Hundal RS, Trajanoski Z. Impaired glucose transport as a cause decreased insulin-stimulated muscle glycogen synthesis in type 2 diabetes. The New Eng J Med 1991;341(4):240-6.

3. Ronald KC. Pathophysiology of Diabetes Mellitus: An Overview. $2^{\text {nd }}$ ed. New York: Mac Millan Publishing Co.; 1994.

4. Fonseca VA. Defining and characterizing the progression of type 2 diabetes. Diabetes Care 2009;32(2):S151-6.

5. Van Gaal LF, Van Acker KL, De Leeuw IH. Repaglinide improves blood glucose control in sulphonylurea-naive type 2 diabetes. Diabetes Res Clin Pract 2001;53(3):141-8.

6. Fuhlendorff J, Rorsman P, Kofod H, Brand CL, Rolin B, MacKay P, et al. Stimulation of insulin release by repaglinide and glibenclamide involves both common and distinct processes. Diabetes 1998;47(3):345-51.

7. Kumar R, Philip A. Gastroretentive dosage forms for prolonging gastric 
residence time. Int J Pharm Med 2007;21:157-71.

8. Kotreka UK, Adeyeye MC. Gastroretentive floating drugdelivery systems: A critical review. Cri Rev Ther Drug Car Sys 2011;28(1):47-99.

9. Soppimath KS, Kulkarni AR, Aminabhavi TM. Development of hollow microspheres as floating controlled-release systems for cardiovascular drugs: Preparation and release characteristics. Drug Dev Ind Pharm 2001;27(6):507-15.

10. Singh BN, Kim BH. Floating drug delivery systems: An approach to oral controlled drug delivery via gastric retention. J Contr Rel 2000;63(3):235-59.

11. Kamath S, Kumar S. Design and evaluation of floating microspheres of rabeprazole sodium. Int J Pharm Pharm Sci 2012;4:357-67.

12. Perumandla PK, Sree P. Formulation and in vitro evaluation of floating microspheres of dextromethorphanhydrobromide. Int J Pharm Pharm Sci 2014;6:206-10
13. Kawashima Y, Niwa T, Takeuchi H, Hino T, Itoh Y. Hollow microspheres for use as a floating controlled drug delivery system in the stomach. J Pharm Sci 1992;81(2):135-40.

14. Patrick JS. Martin's Physical Pharmacy and Pharmaceutical Sciences. $5^{\text {th }}$ ed. Philadelphia, USA: Lippincott Williams \& Wilkins; 2006.

15. Jain SK, Awasthi AM, Jain NK, Agrawal GP. Calcium silicate based microspheres of repaglinide for gastroretentive floating drug delivery: Preparation and in-vitro characterization. J Control Rel 2005;107(2):300-9.

16. Costa P, Lobo JM. Modeling and comparison of dissolution profiles. Eur J Pharm Sci 2001;13(2):123-33.

17. Streubel A, Siepmann J, Bodmeier R. Gastroretentive drug delivery system. Expert Opin. Drug Deliv 2006;3(2):217-33.

18. Fu X, Ping Q, Gao Y. Effects of formulation factors on encapsulation efficiency and release behavior in vitro of huperzine A-PLGA microspheres. J Microencapsul 2005;22(7):57-66 